\title{
Aesthetic Experience in Virtual Museums: A Postphenomenological Perspective
}

\author{
BART G. MOENS, Vrije Universiteit Brussel, Belgium
}

\begin{abstract}
This article explores the impact of the digitization of traditional works of art on the aesthetic experience from a philosophical point of view. Presenting and making use of a recent approach in the philosophy of technology, initiated by the American philosopher Don Ihde, called postphenomenology. This hybrid form of phenomenology builds on traditional phenomenology and combines it with a pragmatic approach in order to focus on the mediating roles of technology. Concrete technologies and applications such as screens and virtual museums are the starting point for our examination of the specific character of these digital media, which are then compared with their physical referents. Following Ihde's arguments, we show that digital image technologies, and digital images themselves, are not merely functional, but shape perceptions and experiences. Although currently the positive effects and opportunities of these new applications are emphasized in the field - for collection management, the democratization and accessibility of art, possibilities to interact and intervene in the image, efficient marketing, etc. - they do have a significant impact on the way in which art is experienced.
\end{abstract}

\section{Key words:}

Digitization of art, Virtual museums, Aesthetic experience, Postphenomenology.

\section{SDH Reference:}

Bart Moens. 2018. Aesthetic Experience in Virtual Museums: A Postphenomenological Perspective.

$\mathrm{SDH}, 2,1,68-79$.

DOI : $10.14434 /$ sdh.v2i1.24468

\section{INTRODUCTION: ANALOG ART GOES DIGITAL}

Over the past decades human society has gone through far-reaching transformations by means of so-called disruptive digital technologies such as the Internet, computers, smartphones, etc. [World economic Forum 2015]. Digital technologies reveal the world in new ways and shake up existing practices. Human experiences, perceptions and practices are increasingly mediated through these technologies. This is certainly the case for our contemporary experience of traditional works of art, as recognized by theorists [Marty and Burton Jones 2008; Parry 2010] and policy makers [European Commission 2011; Flemish Government 2017]. The digital representation of material artifacts plays an important role in the development of this digital turn [Hilbert and Lopez 2011]. Dealing with this global phenomenon, cultural institutions digitize their collections on a large scale to provide new experiences of traditional cultural heritage, thereby responding to the expectations of a contemporary audience. Through the digital disclosure of these objects, material culture is being

Author's address: Bart G Moens, Dept. of Philosophy and Moral Sciences (FILO), Vrije Universiteit Brussel, Pleinlaan 2, 1050, Bruxelles, Belgium; email: bart.g.moens@gmail.com

(c) [2018] by the author; licensee Studies in Digital Heritage, IU, Bloomington (IN), USA. This article is an open access article distributed under the terms and conditions of the Creative Commons Attribution License (CC BY-NC) 
transformed into digital format, and hence incorporated within a broad digital and particularly visually oriented culture.

Because of their distinctly object-centered approach, art museums initially took a rather cautious position towards the use of digital applications, but nowadays the digitization programs of renowned art museums such as the Rijksmuseum in Amsterdam are at the forefront of this digital evolution. The digital pendants of material collections prove to be valuable and necessary additions for different purposes: collection management, exhibition, education, marketing, research, etc. However, in spite of the fact that the use of digital technologies in a cultural heritage context has been the object of discussion since their development [Jones-Garmil 1997; Marty and Burton Jones 2008], their pervasive impact on the aesthetic experience is severely understudied in both theoretical and empirical ways. From one perspective, this is due to the complexity and interdisciplinary nature of the subject, stretching across several disciplines - computer science, museology, art history, digital humanities, etc. - resulting in what Ross Parry calls a "diasporic body of literature" [Parry 2010]. From another perspective it has to do with the rapidity of the technological developments and the popularity of these technologies, which lead to an overall emphasis on a pragmatic approach in the field, with a focus on the integration, the use, and the development of new media tools [Lévy 2010]. To gain a more nuanced understanding about these technologies, and to facilitate a well-informed use, a profound reflection on this multi-layered subject is needed.

From a philosophical viewpoint, these new technologies reframe essential questions on different levels: ontological (how do we relate to the world through digital technologies?), epistemological (how do we know the world through digital technologies?), ethical (how do we behave and make decisions through our use of digital technologies?), and aesthetic (how are our perceptions and experiences mediated through digital technologies?). Focusing on the latter, we turn to the experience of traditional works of art, such as paintings, mediated by digital image technologies. To study the aesthetic implications of digitization in a novel way, we make use of the body of work of the contemporary North-American philosopher of technology Don Ihde ( $\left.{ }^{\circ} 1934\right)$, who has been focusing on the mediating roles of technology since the 1970s from a phenomenological perspective [Ihde 1979], called by him "postphenomenology" [Ihde 1993]. Hence, precisely by way of our fundamental philosophical approach, we can make abstraction of the emphasis on the practical and pragmatic motives in the field.

\section{PRESENTING POSTPHENOMENOLOGY FOR THE STUDY OF DIGITALLY MEDIATED HERITAGE}

Postphenomenologically speaking, art is the product of various human-technology-world relations. This has been the case from the creative use of late-Palaeolithic tools and pigments to produce cave images, to the artistic applications of contemporary digital technologies. Since their origin, visual arts have always been intertwined with technology. Traditionally this was primarily the case for the creation of art, but with our present-day use of digital image technologies, the way we experience art is increasingly mediated through technology as well: digital images of art are being watched online, on all sorts of screens, providing new practices and possibilities to engage with images, such as 
digital image manipulation or zooming. As such, the aesthetic experience has become highly technologically mediated.

This research is thus embedded in a large tradition in the philosophy of art concerning the relation between an original work of art and its copy. Furthermore, since we approach this issue from a recent stream in the philosophy of technology, the research is situated at the crossroads of both philosophical sub-disciplines. This article does not engage in art criticism, in the sense of either digital iconoclasm or iconophilia. The phenomenological methodology is descriptive, and therefore both the original work of art and its digital copy are considered as unique and full-ledged phenomena which can be analyzed in their own context. Nevertheless, considering the ontological connection as an image or a representation of a referent, the differences and similarities between the two will be analyzed. But before undertaking such an analysis, we need to sketch out the philosophical background and the conceptual framework of postphenomenology.

\subsection{Philosophical background}

Postphenomenology is a young discipline in the contemporary philosophy of technology that has been developing since the 1990s from the work of Ihde, examining concrete technologies and their impact on the way we perceive, experience and interpret the world. As its prefix indicates, it builds on phenomenology. First of all, this is evident in its focus on phenomenological intentionality, variation, and description as developed by the German philosopher and founder of phenomenology, Edmund Husserl (1859-1938) [Husserl 1913]. Secondly, it is evident in a focus on the cultural and historical dimensions, the act of interpretation and the non-neutrality of technology, as emphasized by the German philosopher Martin Heidegger (1889-1976) [Heidegger 1927; Heidegger 1954]. Thirdly, there is the significant use by postphenomenology of the concept of embodiment in relation to the world as demonstrated by the French philosopher Maurice Merleau-Ponty (1908-1961) [MerleauPonty 1945]. However, postphenomenology distances itself from the essentialism and the rather deterministic perspective regarding technology, showcased by most traditional phenomenology. Instead of making abstraction of technologies and presenting them as the "opposite" of human beings and nature, according to postphenomenological theory technologies do not create a distance to the world but ensure relations with the world [Ihde 1990]. Postphenomenologists take concrete technologies as the starting point in their study of relations between humans, technologies and the world, from an embodied and contextual perspective, to present a much more empirically rich and nuanced picture of how material artifacts shape our existence. Therefore, postphenomenology is described by Robert Rosenberger and Peter-Paul Verbeek as "[...] the practical study of the relations between humans and technologies, from which human subjectivities emerge, as well as meaningful worlds" [Rosenberger and Verbeek 2015], and it is characterized as "a pragmatic phenomenology of technology" [Brey 2010]. By employing a combination of philosophical analysis and an empirical approach - phenomenological observation, the use of scientific and historical sources to enrich the conceptual analysis, and qualitative empirical research -, postphenomenology connects with an important development in the philosophy of technology described as the "empirical turn" [Achterhuis 2001]. 


\subsection{Conceptual framework}

Ihde's postphenomenology has been gaining influence in the contemporary philosophy of technology over the past several decades. With an emphasis on the constitutive role of technology with regard to scientific knowledge and cultural practices, he gave a new impulse to the philosophy of technology. In his main works Technology and the Lifeworld: From Garden to Earth [Ihde 1990] and Postphenomenology: Essays in a Postmodern Context [Ihde 1993], Ihde develops programs and concepts to analyze the impact of technologies phenomenologically, which have been applied to a wide range of subjects ranging from speed bumps [Rosenberger 2014] to self-tracking technologies [Van Den Eede 2015]. Providing new philosophical tools to question the mediating and constituting roles of technology, postphenomenology is nowadays practiced to explore in particular epistemological and ethical issues, such as the relations between technologies and science that Ihde studies [Ihde 1998; Ihde 2009], and the moral implications of technologies explored by Verbeek [Verbeek 2011] and Rosenberger [Rosenberger 2014]. The aesthetic dimension of technological mediation, however, remains an underdeveloped theme in the field of research, notwithstanding the increased interest in art [Ihde 2018] and media [Van Den Eede et. al. 2017] in recent years.

\subsubsection{Technological texture and technological intentionality}

Ihde interprets objects as active mediators in human actions and perceptions. This implies that human beings do not take a sovereign position in relation to technologies, but are severely affected by technologies, although not in a deterministic way. Hence, postphenomenology positions itself diametrically - as also does, for example, Bruno Latour's Actor-Network Theory - to the traditional subject-object dichotomy, for which subjects are active factors and objects play a passive, solely instrumental role. By contrast, a central thesis in postphenomenological theory holds that technologies are not neutral objects or instruments; human beings and technologies constitute each other, and it is this co-evolution that postphenomenology tries to understand. Moreover, the technological texture of our lifeworld does not only influence our surroundings; it alters our perceptions and conceptions too.

Human beings interact with and experience the world through technologies, which thereby influence the way we perceive the world. Experiencing is, like seeing and thinking, intentionally directed towards phenomena. This intentionality is often mediated through technology. Postphenomenological theory assesses this mediation process in two ways: on the one hand technologies amplify aspects of reality, on the other hand they have a reductive effect. Ihde further points out that people's fascination with new possibilities of innovative technologies allows for the reductive aspects of technologies to stay mostly underexposed. For example, zooming in on a digital image allows us to discover details invisible for the naked eye, which is an amplifying and commonly emphasized effect. On the other hand, the multidimensional encounter with the actual work of art does not take place anymore and the entire sensory gestalt is transformed; the object is reduced to a visual 2D resemblance. This implies that technologies are not neutral instruments but directly affect

\footnotetext{
${ }^{1}$ In contrast to Actor-Network Theory, postphenomenology still distinguishes human and nonhuman actors by looking at two-way relations between human beings and technologies.
} 
our experiences, even though this technological impact seems to withdraw from our daily experiences.

\subsubsection{Human-technology-world relations}

To investigate the process of technological mediation on an individual and a cultural level, Ihde distinguishes various "human-technology-world relations" [Ihde 1990]. A first type of relation is the embodiment relation, which represents the sensory relation with the world through technology. This type of relation often implies the inclusion of technology into our experience and body scheme, e.g., we do not consciously experience our glasses or computer mouse while using them. As MerleauPonty points out, human beings experience the world through their bodies [Merleau-Ponty 1945]. Ihde further develops this argument and points out that when we experience the world through a technology, this technological involvement often becomes "transparent", in the sense that it withdraws from conscious experience. Ihde further relates this Heideggerian notion to a double human desire: a desire for technological transformation of the world, and simultaneously a desire for the absence of the technology itself. As a consequence, the subtler the transformation, the greater the technological transparency. Accordingly, digital images of works of art showcase technological transparency, since these images apparently show the same image in an iconographical and compositional way; however, the experience of a visual object like a painting is not an experience that is exclusively practiced with our eyes. ${ }^{2}$ A second type of human-technology-world relation, then, is the hermeneutic relation, which concerns an interpretative act within a technological context. Contrary to the embodiment relation, the world here is not experienced through a technology but is understood by a technology. As such, a technological object or instrument represents or renders an aspect of the world which can be interpreted, e.g., the numbers on a thermometer indicate the temperature of the surroundings. Although the technology is clearly present, it becomes transparent owing to the hermeneutical focus on the content. Thirdly, the alterity relation comes about when humans relate to technologies as to or with "an other." Ihde derives the term 'alterity' from Emmanuel Levinas (1906-1995), who in his work Totalite et infini uses the word to indicate the fundamental difference between fellow men [Levinas 1961]. This relationship is characterized by feelings of sympathy or attachment towards technologies. A fourth and final human-technology-world relation described by Ihde is the so-called background relation, which describes relations with technologies that do not demand our focal attention but do influence the indirect context of experience. Examples are central heating systems or refrigerators, at work in the background.

\subsubsection{Technologies as cultural instruments}

These human-technology relations and corresponding interactions take place in a cultural context. Nevertheless, in the intertwining of technology and culture, not only technologies are formed; by using technologies, cultures are shaped too. Therefore, Ihde interprets technologies as "cultural instruments"; through their use, technologies play an active role in the creation of perceptions, convictions and practices, although again, not in a deterministic way. For example, ICT applications

\footnotetext{
${ }^{2}$ We will discuss this issue in the course our postphenomenological analysis of digitized works of art (cf. infra 3.2.).
} 
such as the Internet enable an explosion of cultural exchange, thereby mixing up different cultural backgrounds, causing the insufficiency of one interpretational framework, resulting in what Ihde calls pluriculture [Ihde 1990]. Furthermore, he demonstrates that technologies gain their meaning in a cultural context, which implies that technologies can be interpreted in different ways and have no permanent essence and therefore are "multistable".

\section{A POSTPHENOMENOLOGICAL INVESTIGATION OF DIGITIZED WORKS OF ART}

Postphenomenologically speaking, the central research question of this article is as follows: how do digital image technologies mediate the aesthetic experience? From a broad perspective three types of digital heritage can be distinguished: digital-born content such as digital photography, videogames, etc.; digitally stored metadata about cultural heritage; digitized heritage with an analog pendant. We focus on digitized heritage, particularly digital images of existing works of art such as paintings. These digital images can be printed on an analog medium such as paper or canvas, or they can be watched on screens in a virtual environment. Discussing the latter, we turn to so-called virtual museums, online exhibitions, digital heritage platforms, etc.

\subsection{Technologically textured images}

Through the development of powerful microprocessors, storage and network possibilities, and qualitative image technologies, the number of digital images grows exponentially: up to 2 billion images a day in 2014 [De Bosschere 2017]. The emphasis on visual stimuli plays an important role in the development and design of new digital technologies. Hence, our contemporary experience of the world is to a large extent shaped by the images we see through these digital media, and as a result this also applies to the way we experience art. Virtual museums, which have been developed since the nineties, can be situated within this development. They showcase a considerable evolution: from the static digital representations in experimental virtual environments in the early 1990s, to the dynamic and interactive applications we can visit today.

In the case of analog media, images and their carriers are inseparable. By contrast, digital files do not have an independent material existence; they are merely data until they are presented on a screen or printed [Besser 2003]. Before being displayed, images of works of art go through a complex transformation trajectory, called digital imaging, by which an image - i.e. the input of light intensities - is captured by a lens, projected onto a sensor, and subsequently its electrical output is transformed into binary code by a digitizer. When an artefact is transformed into a digital code, the work of art is being stripped of its materiality. Through the hardware and software of a computer system the code is saved and displayed as a visual entity, which can - in contrast to the analog referent - be reproduced infinitely without loss of information. In the final stage, the users experience the image only be means of the device and the layout of the interface: the software is designed in such a way that the code stays hidden during this process [Irwin 2016]. Moreover, the transparency and ambiguity of these digital transformations is increased by familiarity with these technologies, by user-friendly applications and our deeply rooted affinity with omnipresent digital images. 
These technological transformations however impact the way we visually perceive digital images. Even though the digital disclosure of art collections is a scientific process in which objective registration and neutral representation are paramount, the digital transformation has visual consequences. However, these effects are seldom directly experienced due to the focus on the visual content of the image, which - at first sight - has not been altered: the composition and the iconography apparently remain identical. However, despite the scientific registration process, a completely new digital image with unique properties is created. In addition, the recording and the processing of the image are loaded with human and technological agency: the selection of the works, the equipment, the settings, the positioning and lightning, the evolution of technological developments, etc., all play an important role in determining the final result. What is more, notwithstanding the use of standards and procedures, multiple digital recordings of a work of art will never be exactly the same. Moreover, they will also become outdated through time, due to alternations of art works themselves and constant digital developments.

\subsection{Human-digital image technology-world relations}

Not only do the user settings of recording equipment and screens determine digital images, but also more fundamental characteristics of digital media have an impact on how digital images are perceived. Since there is no one-on-one relation between the physical properties of the surface of the screen and the displayed image - the surface of a screen can present many color combinations and images subsequently or simultaneously - images on screens are perceived in a fundamentally different way than are analog images. A screen forms colors through the emission of light, making use of picture elements, or so-called pixels. Visible colors are formed when light beams of the three color channels in the subpixels - blue, green and red - are combined by variation of the voltage of every particular subpixel. A screen thus sends out colors, by means of so-called additive color mixing; this is fundamentally different from the way we perceive traditional media, where light is absorbed and colors are reflected. The specific features of the physical medium thus play a constituting role in the visual properties of images created. Another example of an important visual effect evoked by digital image technologies is that the digital reproduction of certain colors, for example metals such as gold, simply is not possible [Besser 2003].

Furthermore, the surface of a screen is, in contrast to 3D objects, perfectly flat and designed to present 2D images. In that way the possibility to look at a work of art from different angles and several larger - distances is eliminated. When a screen is watched sideways, the image becomes less bright and the reflection on the screen becomes more noticeable. In addition, owing to the 2D registration, and the significant difference between the flexible lens of the human eye and the unbendable photographic lens of a camera, the depth effect changes significantly, even if the image is looked at in front view. These examples showcase the non-neutrality of digital image technologies, as they alter the way art is perceived on what Ihde calls the "microperceptual level", i.e., our sensory experience of the world [Ihde 1990]. ${ }^{3}$

${ }^{3}$ The cultural implication of technologies influence our so-called "macroperception", which we will discuss further in this article (cf. infra 3.3.).

Studies in Digital Heritage, Vol. 2, No. 1, Publication date: September 2018 
With regard to this microperceptual level, technologies provide a framework for action. We physically use the computer mouse, or our fingers on a touchscreen, to navigate an interface, to scroll and to click while other limbs are generally more passive. Looking at digital images on a screen becomes an act of interacting with a technology, particularly using hand-eye coordination. The provided technological possibilities make us perform actions and enable perceptual experiences that are different from an encounter with for example a painting hanging on a wall. The generally static position when watching digital images on a computer or smartphone screen, often slightly bent over, contrasts with the museum visit that is mostly upright, more dynamic and - ironically when one considers mobile devices - more mobile. The materiality and functionality of an object thus play a constituting role in the way we experience art. The experience of watching digital images becomes an embodied computer experience that is fully integrated within our daily use of hardware and software.

The lived experience of a digitized work of art is thus a physical encounter with a digital image technology rather than an encounter with the art object itself. Notwithstanding our intentionality towards the content of a digital image, which causes the visual disappearance - or transparency of the materiality of the used technology, the physical impact is totally different; since digital image technologies transform every dimension of spatial signification. We look at an image on a screen from a certain and fixed distance, completely opposite to what we would usually do when we are interested in a painting we are looking at; here we would go closer to observe the work in more detail or take a few steps back to fully grasp the size of the work. But if we look at an image on a screen from a certain distance, we realize how small are the images viewed on the screen - which are of course relative to the dimensions of that screen. The transformation of the size that in most cases takes place, does not seem to bother us; even if a miniature has the same size as a baroque altarpiece. Consequently, the aesthetic experience is transformed too.

In other cases, works of art are scaled down to the size of thumbnails. The tiny proportions of these images make it possible to navigate quickly and to scroll through hundreds of images in just a few seconds. This presentation of an abundant amount of visual information on a rather small surface provokes more volatile and rather short-lived experiences. This usage of images is in distinct contrast with the way images were looked at in previous times. For example, the symbolic images of medieval times or paintings of German romanticism demand a more unhurried and contemplative eye. The design of the virtual medium, however, with its abundance of possibilities and stimuli, and the permanent distractions surrounding the images in the margin of the screen to capture the user's attention, entails shorter experiences. ${ }^{4}$ In this way these technologies establish another way of seeing.

Seeing requires distance from the eye, but the speed of digital media makes distances relative. Digital images are immediately available on our devices no matter where they are located as long as we can

\footnotetext{
${ }^{4}$ This description is based on our common experience of online exhibitions through web browsers, in which the interface is designed to capture the user's attention and to discover new content. Given the possibilities and the multistability of these technologies, the development of a virtual environment which enables more enduring visual experiences is perfectly possible, or for example through the use of full-screen mode.
}

Studies in Digital Heritage, Vol. 2, No. 1, Publication date: September 2018 
make use of the necessary technological infrastructure. Simultaneously, these new media also create new distances. This digital distance is visualized in the image; the digital image is the proof of the absence of the material object and its physical context. As widely recognized context plays an important role for the aesthetic experience: when religious art is pulled out of its original context with its spiritual atmosphere and staged in a museum, the aesthetic experience of the work will be completely modified. Mobile image technologies in particular offer the user the possibility to choose the preferred surroundings to enjoy art. Instead of visiting a crowded blockbuster exhibition, the viewing of digital reproductions of the same works in the peaceful and solitary surroundings of our living room can be preferred. Nevertheless, the fact that both the museum visit and the enjoyment of digital images in a virtual museum are technologically mediated experiences, the experience of a digital image of a work of art on a screen will always and above all be a technologically mediated experience. Here, Ihde's double desire regarding technology comes in play: we want a technology to improve our relationship with the world - the online presentation and constant availability of art but meanwhile we have the expectation that the technological transformation is as transparent as possible - the illusion that we look at the original works of art.

As stated, an embodied relation with technology implies changes in human abilities with an amplifying or reductive structure. Experiences or perceptions can be amplified in a certain way by a technology, and other aspects of the world can be reduced by that same technology. The possibility of zooming into a digital image is justly interpreted as an important advantage of digital images. In this case technology expands perception, hence seeing becomes seeing by means of technology, thereby providing new perspectives and potentially generating new information. An important consequence of the digital zoom function is that while zooming in, only the zoomed surface is seen, while when we look closely at a real work with our naked eye, the contours of the work stay visible and the physical object keeps the same size. Moreover, in most cases the size of a digitized painting is strongly reduced when viewed on a computer or smartphone screen. We, therefore, can state that in those cases because the images are zoomed out to fit the dimensions of the screen, eventually we zoom in on a zoomed-out image. The zooming tool - previously mainly a tool for scientific investigation - is, however, not just a tool to zoom in. It directs a person's attention and perception, and makes people look at art in different ways. It implies that looking in detail is worthwhile, although most works of art are not created to be experienced aesthetically in such detail. This example illustrates that digital image technologies not only transform what we see and how we look at art, they also create expectations of what we want to see. Accordingly, technologies have cultural implications too; we hereby arrive at the macroperceptual level.

\subsection{Digital image technologies and virtual museums as cultural instruments}

The way we perceive the world on the microperceptual level, is strongly influenced by our cultural conceptions, what Ihde calls "macroperception" [Ihde 1990]. Images are hermeneutically open and in postphenomenological terms "multistable", this means that context plays a key role in the way they are interpreted and acquire meaning. Both images and the virtual environment contain information created by human beings for human beings and require knowledge in order to use and to read them. Although it seems one of the most natural things to do in our visually textured world, understanding images and interpreting pictorial information is a learned skill, as Ihde states: "The photograph, more 
than merely representing, 'teaches' a way of seeing" [Ihde 1993]. A striking illustration of the way image technologies generate ways of seeing on the cultural plane is provided by Nelson Goodman, referring to the work of ethnographer Melville Herskovits:

"More than one ethnographer has reported the experience of showing a clear photograph of a house, a person, a familiar landscape to people living in a culture innocent of any knowledge of photography, and have the picture held at all possible angles, or turned over for an inspection of its blank back, as the native tried to interpret this meaningless arrangement of varying shades of grey on a piece of paper. For even the clearest photograph is only an interpretation of what the camera sees" [Goodman 1968].

Furthermore, the concept and design of virtual exhibitions instantiate a western approach to cultural heritage and the past. This approach is embodied by the enlightenment ideal to collect objects from all over the world and to present them visually to the public, supplemented by the latest scientific information. Through digitization this emphasis on the visual is complete - whereas the object is totally dematerialized.

Additionally, through digital mass media such as the Internet, we learn to look with what Ihde calls a "compound eye," which is pluralistic and cross-cultural [Ihde 1990]. The compound eye requires various cultural frameworks to interpret several cultural expressions at the same time. For example, virtual exhibitions on divergent topics are just a few clicks away: from street art in Senegal, to Russian ethnographic art, to virtual tours of the stately buildings of European museums. Technological possibilities provide new ways of dealing with images: via search engines we work our way through the immense amount of information on the Internet. Google recently developed a visual search engine for Google Cultural Institute which allows one to search for works of art by color or period. In this way technologies influence the way we interpret and experience art. Consequently, we should never regard these technologies as neutral instruments.

\section{CONCLUSION}

Postphenomenological enquiries demonstrate that technologies transform our experiences and knowledge about the world. As such, digital image technologies constitute new experiences of traditional works of art. Although these digital transformations are ambivalent, it is essential to acknowledge and to analyze them. Our spontaneous interactions with these technologies, therefore, need to be questioned on a fundamental level in order to indicate their transparency and to explain the implications of their use. Given our contemporary use of digital applications in the presentation of art and exhibitions, such a postphenomenological analysis needs to be part of the multidisciplinary design phase of digital technologies and exhibitions in order to ensure that these technologies are used in an appropriate and effective way. Moreover, the results of such a reflection should be considered to inform the public about the impact of the used multimedia resources on the way traditional works of art are perceived and experienced.

Ihde's conceptual framework provides a relevant philosophical approach to study these effects of digital image technologies in the cultural heritage field, from aesthetic and epistemological perspectives. As a recent development within the empirical turn of the philosophy of technology, 
postphenomenology enables to study the technologically mediated experience of art in a necessarily multidisciplinary and empirical way. We, therefore, plan to elaborate our (post)phenomenological inquiry of digital images of traditional works of art, supplemented by qualitative research, investigating user experiences in on- and offline exhibitions. Reflection, grounded in empirical data, will contribute to the much needed theoretical and empirical study regarding the use, the effects, and the potential of the omnipresent digital image technologies such as smartphones, computers, VR, $\mathrm{AR}$, etc., in the cultural heritage context.

\section{REFERENCES}

Hans Achterhuis. 2001. American Philosophy of Technology: The Empirical Turn. Trans. R. P. Crease. Bloomington: Indiana University Press.

Philip Brey. 2010. Philosophy of Technology after the Empirical Turn. Retrieved February 1, 2018 from https://www.utwente.nl/bms/wijsb/organization/brey/Publicaties_Brey/Brey_2010_PoT_Empiri cal.pdf.Lévy 2010

Frederik De Bosschere. 2017. De camera vervangt straks je toetsenbord. Retrieved February 2, 2017 from: http://deredactie.be/cm/vrtnieuws/opinieblog/opinie/1.2967530.

European Commission. 2011. Commission Recommendation on the Digitisation and Online Accessibility of Cultural Material and Digital Preservation. Brussels. Retrieved February 1, 2018 from https://ec.europa.eu/digital-single-market/sites/digital-agenda/files/en_4.pdf

Nelson Goodman. 1968. Languages of Art. An Approach to a Theory of Symbols, Indianapolis et. al.: The Bobbs-Merrill Company.

Flemish Government. 2017. Strategische Visienota Cultureel Erfgoed. Brussels. Retrieved February 1, 2018 from http://www.kunstenenerfgoed.be/sites/default/files/uploads/170331_Strategische visienota cultureel erfgoed Vlareg def.pdf

Martin Heidegger. 1927. Sein und Zeit, Halle a. d. Saale: Max Niemeyer.

Martin Heidegger. 1954. Die Frage nach der Technik, Pfullingen: Verlag Günter Neske.

Martin Hilbert and Priscila Lopez. 2011. The World's Technological Capacity to Store, Communicate, and Compute Information. Science 332, 6025 (2018), 60-65.

Edmund Husserl. 1913. Ideen zu einer reinen Phänomenologie und phänomenologischen Philosophie. Erstes Buch: Allgemeine Einführung in die reine Phänomenologie, Halle a. d. Saale: Max Niemeyer

Don Ihde. 1979. Technics and Praxis, Dordrecht: D. Reidel.

Don Ihde. 1990. Technology and the Lifeworld. From Garden to Earth, Bloomington: Indiana University Press.

Don Ihde. 1993. Postphenomenology. Essays in the Postmodern Context, Evanston: Northwestern University Press.

Don Ihde. 1998. Expanding Hermeneutics: Visualism in Science, Easton: Northwestern University Press.

Don Ihde. 2009. Postphenomenology and Technoscience: The Peking University Lectures. Philosophy of the Social Sciences, Albany: SUNY Press.

Don Ihde. 2017. TechnoArt. In Joseph C. Pitt and Ashley Shew eds. The Routledge Companion to 
Philosophy of Technology. New York and London: Routledge.

Stacey Irwin. 2016. Digital Media. Human-Technology Connection, London: Lexington Books. Katherine Jones-Garmil ed. 1997. The Wired Museum: Emerging Technology and Changing Paradigms, Lanham: Rowman \& Littlefield Publishers.

Emmanuel Levinas. 1961. Totalité et Infini. Essai sur l'extériorité, Den Haag: Martinus Nijhoff. Pierre Lévy. 2010. Building a Universal Digital Memory. In R. Parry ed. Museums in a Digital Age. London and New York: Routledge. 107-115.

Maurice Merleau-Ponty. 1945. La phénoménologie de la perception, Paris: Librairie Gallimard.

Netwerk Digitaal Erfgoed. 2015. Nationale Strategie Digitaal Erfgoed. Den Haag. Retrieved February 1, 2018 from

http://www.den.nl/art/uploads/files/Publicaties/Nationale_Strategie_Digitaal_Erfgoed_MinOCW .pdf

Ross Parry ed. 2010. Museums in a Digital Age, London \& New York: Routledge.

Marty Paul and Katherine Burton Jones eds. 2008. Museum Informatics. People, Information and Technology in Museums, New York and London: Routledge.

Robert Rosenberger. 2014. Multistability and the Agency of Mundane Artifacts: From Speed Bumps to Subway Benches. Human Studies 37, 3 (2014), 369-92.

Amit Sood. 2016. From self-portraits to street art: 1,000 museums at your fingertips. Retrieved on February 1, 2018 from https://blog.google/topics/arts-culture/from-self-portraits-to-street-art$1000 /$

World Economic Forum. 2015. "Understanding the Impact of Digitalization on Society." Retrieved February 1, 2018 from http://reports.weforum.org/digital-transformation/understanding-theimpact-of-digitalization-on-society/.

Yoni Van Den Eede. 2015. Tracing the Tracker. A Postphenomenological Inquiry into Self-Tracking Technologies. In R. Rosenberger and P.-P. Verbeek eds. Postphenomenological Investigations. Essays on Human-Technology Relations. Lanham et. al.: Lexington Books, 143-158.

Yoni Van Den Eede, Stacey Irwin and Gallit Wellner. 2017. Postphenomenology and Media: Essays on Human-Media-World Relations, London: Lexington Books.

Peter-Paul Verbeek. 2011. Moralizing Technology: Understanding and Designing the Morality of Things, Chicago: Chicago University Press.

Received February 2018; revised August 2018; accepted August 2018. 